\title{
SOURCE OF POSITRONS ON THE BASE OF LINAC LUE-40
}

\author{
S.A. Perezhogin ${ }^{1}$, E.V. Bulyak ${ }^{1,2}$, V.A. Kushnir ${ }^{1}$, V.V. Mytrochenko ${ }^{1}$, L.I. Selivanov ${ }^{1}$ \\ ${ }^{1}$ National Science Center "Kharkov Institute of Physics and Technology", Kharkiv, Ukraine; \\ ${ }^{2}$ V.N. Karazin Kharkiv National University, Kharkiv, Ukraine \\ E-mail:psa@kipt.kharkov.ua
}

The results of the numeral studies of the source of positrons for NSC KIPT are presented. The positrons are to produce from conversion of the $40 \mathrm{MeV}$ electrons. The bunches of such electrons will be provided by the linac LUE-40. The estimations of yield of the positrons, their spectrum, and spatial-angular distribution are produced. The possibility of the spectrum modification with help of the RF resonator adjusted to the sub-harmonics of the RF frequency is proposed. It is shown that the use of such device allows to substantially increase the number of positrons with small energy. It allows to promote efficiency of the moderation process and increase yield of the slow mono energetic positrons. The optimal parameters of conversion target have been defined. The preliminary calculations of the system of forming the positron bunch are presented as well.

PACS: 41.75.Ht, 25.20.-x

\section{INTRODUCTION}

Application of monochromatic positron bunches with energy to $1 \mathrm{MeV}$ opens unique possibility to carry out research in the technology of materials. Thus, the method of positron annihilation spectroscopy allows to determine both the electronic structure of crystals and various defects of extremely small sizes in the solids and the porous systems, such as vacancies, vacancy clusters and voids of the cubic nanometer scale. All these methods have already got a widespread application in the modern technology of materials, particular in the atomic and electronic material technology $[1,2]$.

In NSC KIPT the positrons are assumed to be obtained converting the bunch of relativistic electrons [3] with energy $40 \mathrm{MeV}$ from the linac LUE-40. Presently on the base of linacs with energy from 10 to $70 \mathrm{MeV}$ [4 - 6] there have been created the installations for research the properties of materials by the positron annihilation spectroscopy methods.

The positron bunch on the exit of conversion target has specific properties: a large power spread, a large angular spread, and a relatively small radius (millimeter scale). Such combination of parameters, especially specific shape of the positron bunch emittance, does not allow for direct acceleration, slowing down the positrons, or to transport them to the experimental setup: the phase portrait of positron bunch has a small transversal size, but large divergence. It is necessary to reform the positron bunch and to clean out the passed through the converter electrons, which number even exceeds that of positrons.

An aim of such transformation of phase portrait of bunch is reduction of divergence due to the corresponding increase of cross-sectional of positron bunch. As a result, a bunch can be transported on considerable distance, as an increase of transversal sizes at transporting is proportional to divergence. This transformation named the concordance of bunch emittance with the system acceptance of further acceleration or deceleration comes true by the magnetic systems, mainly two types: adiabatic adapter, Adiabatic Matching Device (AMD) and Quarter Wave Transformer (QWT).

These devices are similar on principle of action: both use the longitudinal (solenoid) magnetic field.

\section{COMPUTED SIMULATION OF AMD}

We have simulated the process of forming the positron bunch in $6 \mathrm{D}$ phase space. Along with the transformation of phase portrait of bunch in the transverse phase plane when applying Adiabatic Matching Device (AMD) we have considered the possibility of change of the positrons spectrum.

According to the "classic" scheme of obtaining the mono-energy positron bunch, the positrons after the electron-to-positron converter with the typical energy of a few Megaelectronvolt enter a special device - moderator. On the exit of moderator the positrons energy is reduced to a few electronvolt. The efficiency of such transformation substantially depends on the energy of incoming positrons - the greater it is, the less is the efficiency of moderation. In the process of reduction of falling positrons energy from $1 \mathrm{MeV}$ to a few $\mathrm{keV}$, the efficiency of moderator increases more than tenfold [7].

Therefore, there is a task of preliminary reduction of the energy of positrons entering a moderator. One of possible solutions consists in the use of RF-resonator adjusted to a subharmonic of the linac operating frequency (this idea was pioneered in ANL [8]).

The second, not less important, function of the premoderator based on the RF-resonator is to separate the positrons and the electrons emitted from the conversion target. The essence of problem consists in that the target generates the approximately equal streams of the positrons and the secondary electrons. (A small difference between electrons and positrons consists in that the latter can annihilate in a target body). In the longitudinal magnetic field of a matching device the trajectories of electrons and of positrons are similar, only differ by the sign of the rotation angle. The electric field of the premoderator "distinguishes" positrons from electrons: the resonator will slow down the positrons whilst accelerate the electrons, which will be substantial for the further forming of the stream of slow positrons.

The numerical simulation has been carried out by means of the packages GEANT4 [9] and PARMELA $[10,11]$. The PARMELA code is capable to simulate the charged particles dynamics in external magnetic field and at presence of RF-resonators. By means of the PARMELA, the bunch of electrons at the accelerator output is simulated. The data obtained then are passed 
into the program GEANT4, where interaction of the accelerated electrons with the conversion target is simulated. The parameters of the positron stream are determined as a result. Then these parameters are entered into the PARMELA in order to compute the positron bunch dynamics.

Thus, we modeled the entire system, taking into account acceleration of the electrons in the linac, generation of positrons in the target, and transporting and deceleration of the positrons.

The parameters of electron bunch input in the simulation are chosen similar those of the LUE-40 linac, [12]. LUE-40 is a two-section linac, the first section can accelerate electrons up to $40 \mathrm{MeV}$. Since the accelerating sections are of "Kharkov-85" type with comparatively large impedance, the gain of energy of bunch with nonzero current is scaled with current as $66 \mathrm{MeV} / \mathrm{A}$. The filling time of the section at working frequency equals to $0.92 \mu \mathrm{s}$, which is comparable with the pulse width of bunch, $1.5 \mu \mathrm{s}$. Therefore the transition process may not be neglected: it is necessary to carry out the simulation of the self-consistent dynamics of the accelerating electrons. We did it making use the codes such as SUPERFISH/POISSON [13], PARMELA [11], and methods described in [14].

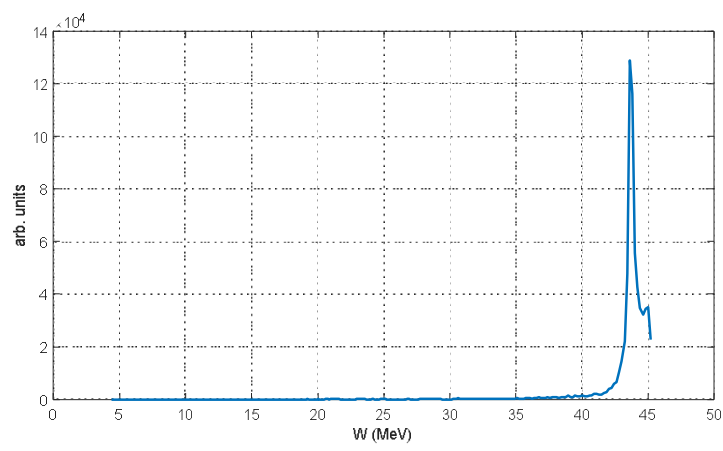

Fig. 1. Integral spectrum of electrons on the exit of $L U E-40$

The simulation has been carried out for the following parameters: the working frequency of accelerating section is $2797.15 \mathrm{MHz}$, the initial energy of particles $25 \mathrm{keV}$, the input current $0.15 \mathrm{~A}$, the RF-power in the section $12 \mathrm{MW}$, duration of the RF pulse $3.0 \mu \mathrm{s}$, duration of the front and the cutoff of the RF pulse $0.42 \mu \mathrm{s}$, the width of the electron bunch $1.5 \mu \mathrm{s}$, the front and the cutoff impulse of the bunch $21 \mathrm{~ns}$, delay of the bunch from the RF pulse $0.35 \mu$ s, the coefficient of coupling of the injector resonator to the feeder is 5, and its Q-value and shunt impedance 3000 and $3 \mathrm{MOhm} / \mathrm{m}$, respectively.

As a result of simulation of self-consistent dynamics, the bunch of electrons acquires the following parameters: the average energy $43.2 \mathrm{MeV}$, the width of spectrum $3.2 \%$, the bunch dimensions $x=0.26 \mathrm{~mm}$, $y=0.26 \mathrm{~mm}$. The integral spectrum of electrons on the exit of the section is presented in Fig. 1.

In Fig. 2, dependence of the total yield of positrons per electron impinging the target, on the target thickness is presented.

The simulation has been carried out for the total number of electrons $3.4 \cdot 10^{6}$, which provide the sufficient number of positrons for subsequent processing.

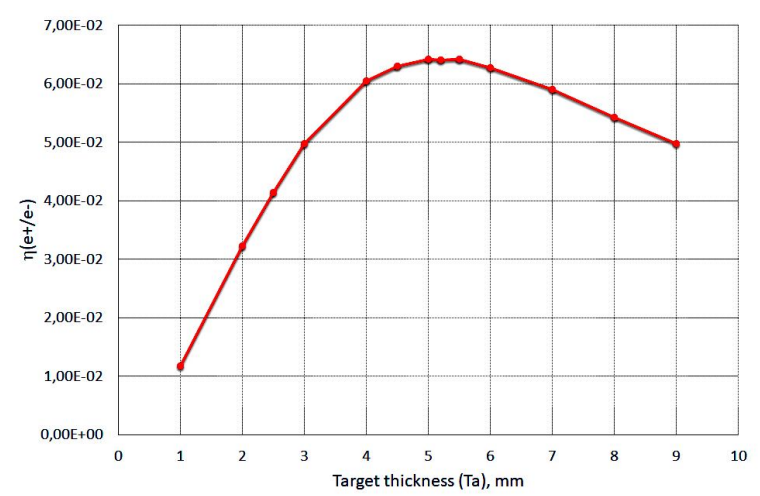

Fig. 2. Total yield of positrons depending on the thickness of target

As is obvious from Fig. 2, the best quantitative result is obtained for a target $5 \ldots .5 .5 \mathrm{~mm}$ thick. The spectrum of positrons exit the $5 \mathrm{~mm}$ thick target is presented in Fig. 3.

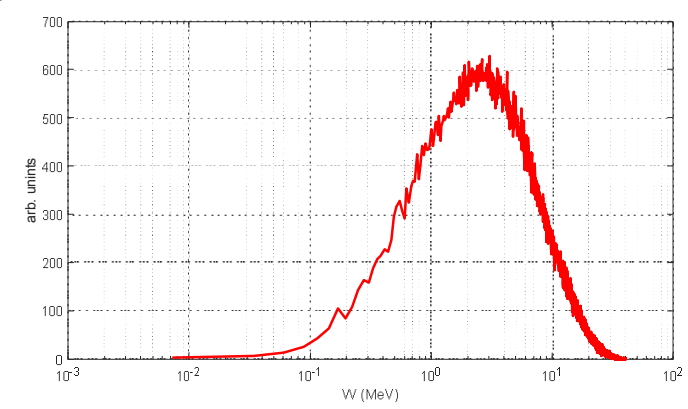

Fig. 3. Spectrum of positrons on that exit of $5 \mathrm{~mm}$ thick converter

As it is obvious from Fig. 3, the fraction of positrons with energies $\leq 200 \mathrm{keV}$ is small, about $0.25 \%$. Further we aimed the simulation to the increase this low-energy fraction of the spectrum. For reduction of the energy of positrons, two RF-resonators have been used, in which the field is set to decelerating phase related to positron bunch.

In Fig. 4 a sketch of the matching system used in simulation is presented. Between the conversion target and the RF-resonators operated as a premoderator, Adiabatic Matching Device is located (the principle of AMD operation is described in [3]). In addition to rotation of the phase space ellipse, the declining magnetic field allows to decrease the average transverse momentum of positrons after passing the AMD.

We have considered the possibility to employ two RF-resonators for more effective deceleration of positrons. In Fig. 4, the red lines and points inside the resonator represent the spatial distribution of the field and the direction of the vector of electric field.

The calculation of RF-resonators has been carried out with the code SUPERFISH [14]. The resonators are adjusted to the frequency $111.88 \mathrm{MHz}$ (25-th subharmonic of linac's working frequency $2797.15 \mathrm{MHz}$ ). The inner radius of the resonator is $7 \mathrm{~cm}$, total length of effective RF-field taking into account the falls along the axis $\mathrm{z}=60 \mathrm{~cm}$. Each RF-resonator has its RF-input of power, allowing to change the field phase in resonators independently. The geometry of resonators is chosen such that allows to shorten the transversal sizes of RFsystem, as well as to place them maximally close to the elements of the positron transport system (AMD). 


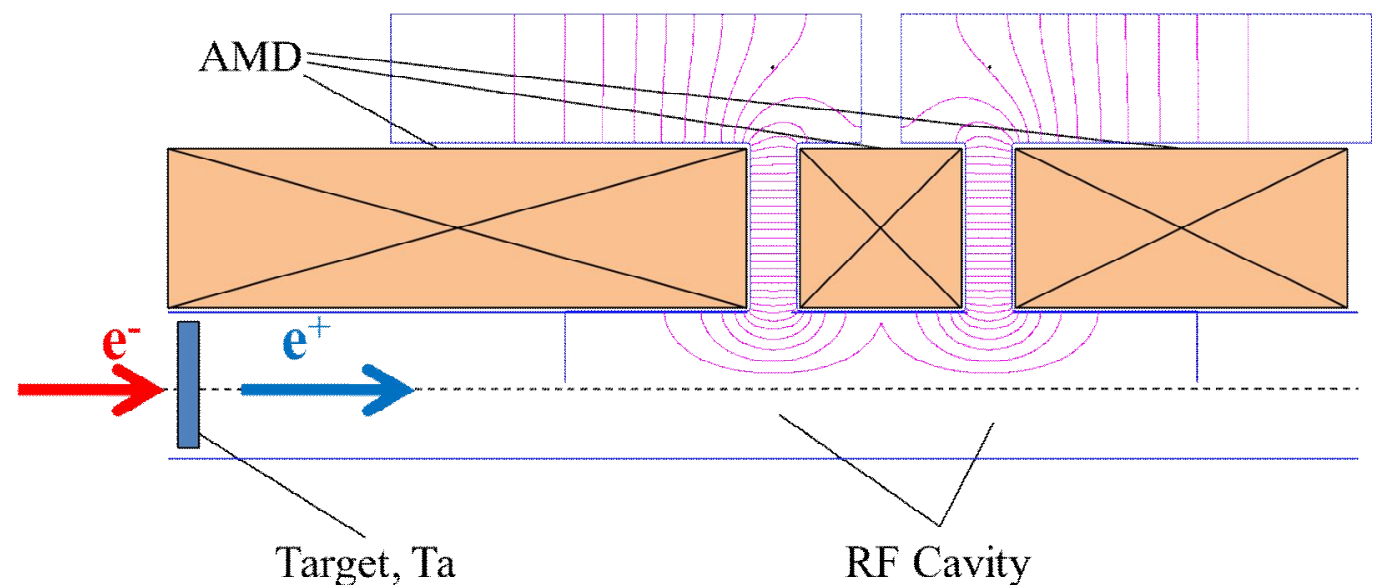

Fig. 4. Sketch of the matching system

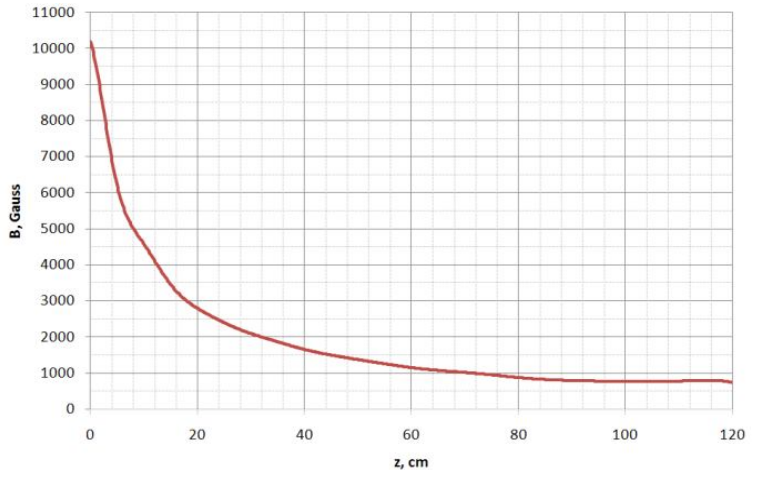

Fig. 5. Magnetic field strength along the axis of AMD, from a target to the exit of $R F$-resonator

In order to obtain relatively small root-mean-square (RMS) divergence of positron beam, we optimized the parameters of AMD by variation of its length and the magnetic field strength. In AMD the magnetic field strength along $\mathrm{z}$ axis gradually decreases from $\mathrm{B}_{0} \approx 10 \mathrm{kGs}$ to $800 \mathrm{Gs}$ (length of AMD is $78 \mathrm{~cm}$ ). The field in AMD satisfies the equation $B_{z}(r=0)=\frac{B_{0}}{1+\alpha z}$

(with $\alpha=0.13$ ). It is shown that near to the optimal magnetic field along drift space and RF resonator is $0.8 \mathrm{kGs}$. The change of magnetic-field along the beamline, from a target to the exit of resonator is presented in Fig. 5.

As a result of optimization of magnetic field, the necessary transformation of the phase distribution of positrons has been obtained in plane $x^{\prime}=p_{x} / p, x$ (Fig. 6).
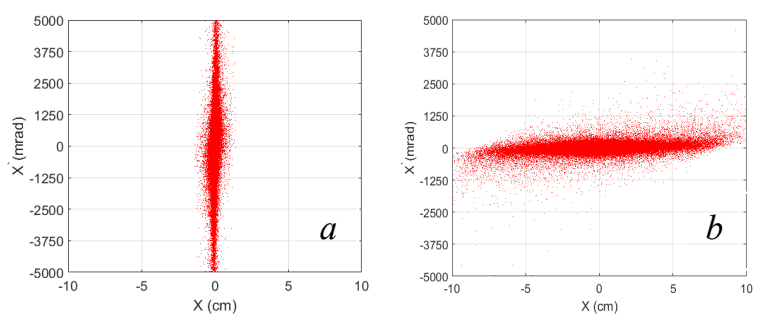

Fig. 6. Phase portrait of positron bunch:

$a$-at the input of AMD; $b$ - at the exit of AMD

By variation of the field amplitude and the phase shift between RF resonators, as well as the initial phase of injection of positrons in RF resonator, the satisfactory deceleration of positrons have been obtained. In Fig. 7, the distribution of the amplitude of electric field is presented on an axis for two resonators.

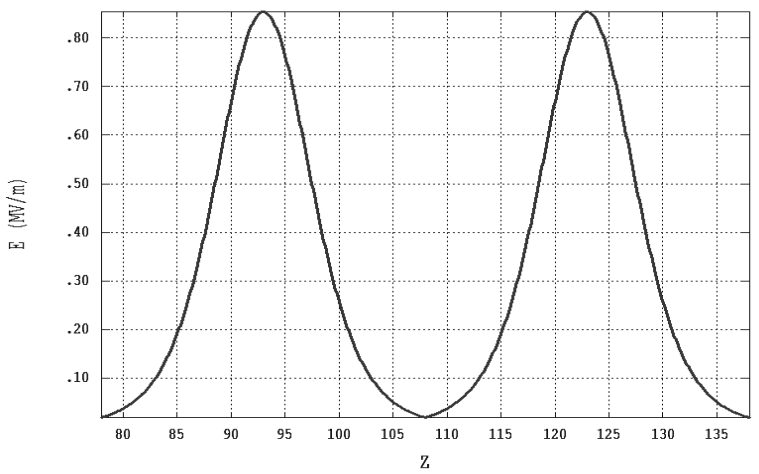

Fig. 7. Amplitude of electric field on the axis for two $R F$ resonators

In Fig. 8 the spectra of positrons are presented at the input of AMD (the spectrum from the conversion target) and after passing the two resonators in the decelerating phase of electric field.

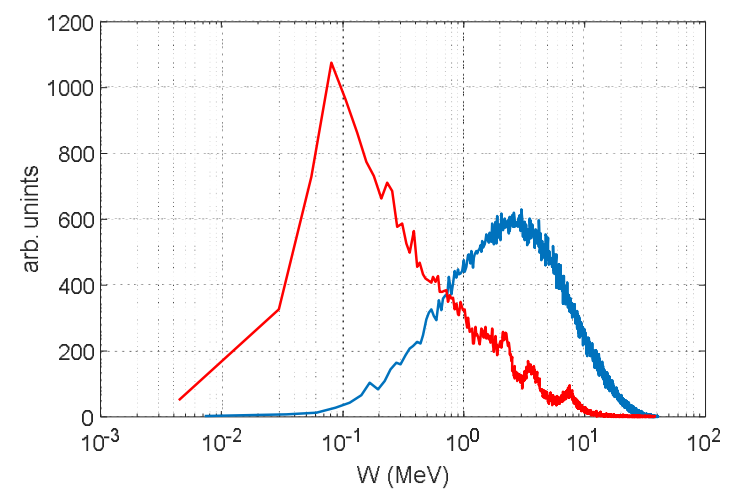

Fig. 8. Power spectrum of positrons at the input of AMD (blue curve) and at the exit of decelerating $H F$ resonator (red curve)

As it is obvious from Fig. 8, employment of the RFresonators allows to decrease the energy of a considerable fraction of the positron bunch. Thus, the energy of positrons at the maximum of spectrum is $80 \mathrm{keV}$. In range from 0 to $200 \mathrm{keV}$ there are contained $10 \%$ of positrons output from the decelerating resonator.

\section{CONCLUSIONS}

The numerical simulation of matching system was performed aimed at confirmation the theoretical estimations accuracy, optimization of the system for the specific parameters of the accelerated electron beam and the conversion target. 
The idea of application of premoderator intended for the increase of efficiency of the planned moderator was suggested.

As a result of theoretical analysis and subsequent numeral design, the possibility to obtain the bunch of low-energy positrons was conformed for the realizable magnetic field and the existing accelerators.

A principal possibility of employment of the decelerating RF field for the increase of the number of slow positrons from initial higher-energy spectrum are also demonstrated.

\section{REFERENCES}

1. R.W. Siegel. Positron annihilation spectroscopy // Annual Review of material science. 1980, v. 10, p. 393-425.

2. Aditya Narayan Singh. Positron ammihilation spectroscopy in tomorrows material defect studies // $\mathrm{Ap}$ plied Spectroscopy Reviews. 2016, p. 1-48.

3. S. Perezhogin, E. Bulyak, A. Dovbnya, V. Mitrochenko, A. Opanasenko, V. Kushnir. KIPT Positron Source Project. Conceptual Design // arXiv preprint arXiv: 1806.00247

4. R. Wada, T. Hyodo, T. Kasuge, et al. New experimental station at KEK Slow Positron // Facility. Journal of Physics: Conference Series 444. 2013, 012082.

5. B.E. O'Rourke et al. Recent Developments and Future Plans for the Accelerator Based Slow Positron Facilities at AIST // Materials Science Forum. 2013, v. 733 , p. $285-290$.

6. S. Chemerisov and C.D. Jonah. Development of the Positron Facility at the Argonne National Labora- tory's $20 \mathrm{MeV}$ Linac // Materials Science Forum. 2009, v. 607, p. 243-247.

7. B.E. O'Rourke, N. Hayashizaki, A. Kinomura, R. Kuroda, E. Minehara, T. Ohdaira, N. Oshima, and R. Suzuki. Simulations of slow positron production using a low energy electron accelerator // arXiv:1102.1220 v2[physics. Acc-ph] 10 May 2011.

8. J. Long, S. Chemerisov, W. Gai, C.D. Jonah, W. Liu, H. Wang. Study on high flux accelerator based positrons source // Proceedings of PAC07. Albuquerque, New Mexico, USA. p. 2921-2923.

9. A toolkit for the simulation of the passage of particles through matter. Geant 4 code // In https: //cern.ch/geant4. 2007.

10. Lloyd Young and James Billen. The Particle Tracking Code PARMELA // PAC'2003. Portland, May 2003, p. 3521.

11. L.M. Young. PARMELA // Los Alamos: 1996.93 p. (preprint / Los Alamos National Laboratory, LAUR-96-1835).

12. N.I. Ayzatsky, V.I. Beloglazov, V.P. Bozhko, et al. Electron $100 \mathrm{MeV}$ linac based facility to nuclearphysical experimental investigation // Problems of Atomic Science and Technology. Series "Nuclear Physics Investigations”. 2010, № 2, p. 18-22.

13. J.H. Billen and L.M. Young. POISSON/SUPER-FISH on PC compatibles // Proc. 1993 Particle Accelerator Conff. Washington (USA). 1993, p. 790-792.

14. V.V. Mytrochenko, A. Opanasenko. Study of transient self-consistent beam dynamics in RF linacs using a particle tracing code // NIM. 2006, A 558, p. 235-239.

Article received 12.02.2020

\section{ИСТОЧНИК ПОЗИТРОНОВ НА БАЗЕ ЛИНЕЙНОГО УСКОРИТЕЛЯ ЭЛЕКТРОНОВ ЛУЭ-40 С.А. Пережогин, Е.В. Буляк, В.А. Кушнир, В.В. Митроченко, Л.И. Селиванов}

Представлены результаты проведенных численных исследований источника позитронов, который проектируется в ННЦ ХФТИ. Позитроны предполагается получать конвертированием пучка релятивистских электронов с энергией 40 МэВ. Исследована возможность изменения энергетического спектра позитронов с помощью СВЧ-резонатора, настроенного на субгармонику частоты прохождения электронных сгустков. Показано, что использование такого устройства позволяет существенно увеличить число позитронов с малой энергией. Это позволяет повысить эффективность процесса модерации позитронного пучка и увеличить выход медленных моноэнергетичных позитронов. Исходный электронный пучок реализуется на линейном ускорителе электронов ЛУЭ-40. Произведены оценки выхода позитронов, их спектров, а также пространственно-угловых характеристик. Определены оптимальные параметры конверсионной мишени. Проведен предварительный расчет системы формирования позитронного пучка.

\section{ДЖЕРЕЛО ПОЗИТРОНІВ НА БАЗІ ЛІНІЙНОГО ПРИСКОРЮВАЧА ЕЛЕКТРОНІВ ЛУЕ-40}

\section{С.О. Пережогін, С.В. Буляк, В.А. Кушнір, В.В. Митроченко, Л.І. Селіванов}

Представлено результати проведених чисельних досліджень джерела позитронів, яке проектується в ННЦ ХФТІ. Позитрони передбачається отримувати конвертуванням пучка релятивістських електронів 3 енергією $40 \mathrm{MeB}$. Досліджено можливість зміни енергетичного спектра позитронів за допомогою СВЧрезонатора, налаштованого на субгармоніку частоти проходження електронних згустків. Показано, що використання такого пристрою дозволяє істотно збільшити число позитронів 3 малою енергією. Це дозволяє підвищити ефективність процесу модерації позитронного пучка і збільшити вихід повільних моноенергетичних позитронів. Вихідний електронний пучок реалізується на лінійному прискорювачі електронів ЛУЕ-40. Проведено оцінки виходу позитронів, їхніх спектрів, а також просторово-кутових характеристик. Визначено оптимальні параметри конверсійної мішені. Проведено попередній розрахунок системи формування позитронного пучка. 